\title{
Use of Contraceptive Methods Among Women Seeking Safe Abortion Services in a Family Planning Center, Kathmandu, Nepal
}

\author{
Sapana Shrestha*1, Renuka Pradhananga ${ }^{2}$, Ramesh Shrestha ${ }^{3}$, Tulza \\ $\mathrm{KC}^{4}$
}

${ }^{1}$ Master in Nursing in Women's Health and Development, Institute of Medicine, Maharajgunj, Kathmandu, Nepal. 2Professor, Department of Women's Health and Development, Institute of Medicine, Maharajgunj, Kathmandu, Nepal. ${ }^{3}$ Assistant professor, Department of Obstetrics and Gynaecology, B. P. Koirala Institute of Health Sciences, Dharan, Nepal. ${ }^{4}$ Lecturer, Department of Medical and Surgical Nursing, Institute of Medicine, Maharajgunj, Kathmandu, Nepal.

\begin{abstract}
Aims: The aim of the study was to assess the use of contraceptive methods among women seeking safe abortion services in a family planning center, Kathmandu. Methods: It was a descriptive cross sectional study undertaken among 119 women seeking safe abortion services from August 18 to September 2018 at Marie Stopes Center, Gongabu, Kathmandu. Non- probability purposive sampling technique was adopted and data were collected through face to face interview. The collected data was analyzed by SPSS version 16 using descriptive statistics and inferential statistics. Results: Among a total of 119 respondents enrolled in the study, a total of 90 (75.64\%) women used post abortion contraceptive methods. Among them, nearly half $(44 ; 48.9 \%)$ had used oral contraceptive pills and least users were IUCD $(19 ; 14.4 \%)$. More than half $(67 ; 56.3 \%)$ had terminated the current pregnancy due to the reason of completed family. Almost three-fifth of them $(50 ; 57.47 \%)$ had history of discontinuation of family planning methods in the past due to side effects. Similarly, almost three-fifth $(68 ; 57.1 \%)$ had preferred medical abortion for termination of the current pregnancy. There was statistically significant association between post abortion contraceptive use with educational level ( $p=0.01)$, parity $(p=0.000)$, contraceptive use in past $(p=0.012)$, plan of future pregnancy $(p=0.001)$, and family planning discussion with husband/partner $(p=0.000)$. Conclusion: There is an increasing trend in the use of some forms of post-abortion contraceptive measures in Nepal from 56.0\% in 2014 to $75.64 \%$ in 2018 after surgical or medical abortion. Among the post-abortion contraceptive non-users, more than half denied use of post-abortion contraceptives due to fear of side effects. Hence, raising the knowledge, attitude, practice and social awareness of post-abortion contraceptive use among women of reproductive age groups would certainly reduce undue fear of the use of post-abortion contraceptive use, its side effects and also help to raise the acceptance and compliance of its use.
\end{abstract}

Keywords: Contraceptive methods, family planning, post-abortion, safe abortion.

\footnotetext{
* Address of Correspondence: Dr. Sapana Shrestha, Ghopa camp, Dharan-18, Sunsari, Nepal.

Email address: sapanashrestha484@gmail.com

(Received 24 December 2019; revised 12 January 2020; accepted 17 January 2020)
} 


\section{Introduction}

Contraceptive is the artificial or natural means used to prevent conception. About half of the unexpected pregnancies in developing countries are terminated, so WHO emphasizes the importance of providing family planning services after abortion (1). The goals of comprehensive abortion care program are to provide safe, high quality services to women in an affordable and acceptable way to reduce the maternal mortality and morbidity (2).

Abortion is an issue which affects every country in the world. Unintended pregnancies continue to be a major global tragedy for millions of women (3). Unplanned or unintended pregnancy poses a major economic, psychological, social, and religious challenge in women of reproductive age especially in developing countries (4). Despite the availability of a modern and effective contraceptive, it is one of the leading causes of maternal mortality and morbidity in developing countries due to unsafe and septic abortion practices (5). There is a strong correlation between abortion and contraception use, where as abortion incidence declines as contraceptive use increases in settings with steady fertility rates over time (6).

Post abortion contraception counseling is the provision of contraceptive services at a time immediately following induced abortion or post abortion care is an essential element of abortion care (7).

A study conducted in 2014 by Padmadas et al. in Nepal about contraceptive behavior among women after abortion showed that there was low level of post abortion contraceptive use and high rates of discontinuation, especially among women using modern temporary methods and only $56 \%$ of women had an abortion initiated contraceptive use in the 12 months following the procedure (8). This study was conducted to assess the practice of post-abortion contraceptive use among women seeking safe abortion services in Kathmandu and its changing trends and social acceptances.

\section{Aims and Objectives}

The aims of this study was to assess the practice of contraceptive methods among women seeking safe abortion services in a family planning center, Kathmandu, Nepal changing scenario and the factors affecting the use.

\section{Materials and Methods}

This was a descriptive cross sectional study conducted in Marie Stopes Center, Gongabu Kathmandu from $19^{\text {th }}$ September to $19^{\text {th }}$ October, 2018. Marie Stopes Nepal is an international organization which provides safe abortion services, free services in family planning counseling and contraceptives, post abortion family planning services and sexual reproductive health services.

\section{Inclusion criteria}

The inclusion criteria were women of any age who came for safe abortion and/or post abortion care services irrespective of their marital status.

\section{Exclusion criteria}

Exclusion criteria were women who had complications after safe abortion services and who refused participation and denied written consent.

Purposive sampling technique was used to sample the participants. The study was undertaken after obtaining the ethical approval from the Institutional Review Committee of Institute of Medicine, Maharajgunj and formal permission taken from board of Marie Stopes Center, Gongabu. Informed written consent was obtained from the clients before the face to face interview.

According to population-based data of Nepal 2014 , only $56.0 \%$ of women had an abortion initiated contraceptive use in the 12 months following the abortion procedure (8). Assuming the proportion of post abortion contraceptive acceptance as $56.0 \%$ and using the formula for infinite population.

$\mathrm{n}=\mathrm{z} 2 \mathrm{pq} / \mathrm{d}^{2}$

Where $\mathrm{n}=$ sample size

$\mathrm{Z}=\mathrm{Z}$ value taken from normal table which is 1.96 at $95 \%$ confidence interval

$\mathrm{q}=1-\mathrm{p}$

$\mathrm{d}=$ desirable permissible error $( \pm 5 \%)=0.05$

$1.96 \times 1.96 \times 0.56 \times 0.44 / 0.05 \times 0.05=378.62$

For adjusted sample size estimation,

The average number of women seeking safe abortion services in Marie Stopes Center, Gongabu, Kathmandu is about 150 per month.

Hence, $\mathrm{N}=150$

Now, formula for finite population sample size

$\mathrm{n} 0=\mathrm{n} / 1+\mathrm{n} / \mathrm{N}$

$378.62 / 1+378.62 / 150=107.43$

Sample size $=107.43$

Now, including 10\% non-response rate, $107.43+$ 10.74=118.17 119 
The required sample size for this study was 119. Socio demographic profile, reproductive history, reproductive knowledge, contraceptive history, contraceptive knowledge and reason for terminating pregnancy were the baseline variables which were entered in preformed questionnaire. Questionnaire for study were semi structured interview schedule adapted based on related literature review. The questionnaire was prepared in English and then translated in to Nepali language. The Nepali version was again translated back to English version to check for consistency of meaning.

Data obtained in excel chart were entered in SPSS version 16. Categorical variables are expressed as frequency (percentages) and continuous variables as mean $\pm \mathrm{SD}$ and median (IQR). Chisquare test is used to calculate the association between the various socio-demographic variables and post-abortion contraceptives use and $P$ val$u e \leq 0.05$ is considered as significant association.

\section{Results}

A total of 119 respondents were enrolled in the study from $19^{\text {th }}$ September, 2018 to $19^{\text {th }}$ October, 2018.

The median age of the respondents was 29 years (Range=17-46 years). Most of the respondents (97; 81.6\%) were Hindu by religion. Most of them (105; 88.2\%) were married. Almost all of them $(110 ; 92.4 \%)$ were literate and almost half of them $(63 ; 52.9 \%)$ were home maker by occupation. Majority of them $(84 ; 70.58 \%)$ were multipara. Two fifth of the respondents $(51 ; 42.85 \%)$ had history of previous abortion. Similarly, three fifth of the respondents

Table 1: Socio-demographic characteristics of the respondents $(n=119)$

\begin{tabular}{|l|l|}
\hline Characteristics & Number (Percentage) \\
\hline Median age in years (Range) & $29.14(17-46)$ \\
\hline Religion & \\
\hline Islam & $2(1.6)$ \\
\hline Buddhism & $20(16.8)$ \\
\hline Hinduism & $97(81.6)$ \\
\hline Marital Status & \\
\hline Unmarried & $14(11.8)$ \\
\hline Married & $105(88.2)$ \\
\hline Educational Status & \\
\hline Illiterate & $9(7.6)$ \\
\hline Literate & $110(92.4)$ \\
\hline Occupation & \\
\hline Unemployed(student) & $11(9.2)$ \\
\hline Business & $14(11.8)$ \\
\hline Service (Government/private) & $31(26.1)$ \\
\hline Homemaker & $63(52.9)$ \\
\hline Parity & \\
\hline Nullipara & $28(23.54)$ \\
\hline Primipara & $7(5.88)$ \\
\hline Multipara & $84(70.58)$ \\
\hline Previous History of Abortion & \\
\hline Yes & $51(42.85)$ \\
\hline No & $68(57.15)$ \\
\hline Gestational Age of Current Pregnancy (Weeks) & \\
\hline$<9$ Weeks & $111(93.3)$ \\
\hline 9-12 weeks & $8(6.7)$ \\
\hline Termination of Current Pregnancy & \\
\hline & \\
\hline
\end{tabular}




\begin{tabular}{|l|l|}
\hline Surgical Abortion & $51(42.9)$ \\
\hline Medical Abortion & $68(57.1)$ \\
\hline Reason for Terminating the Current Pregnancy & \\
\hline Accidental drug intake during pregnancy & $3(2.5)$ \\
\hline Medical disorders & $4(3.4)$ \\
\hline Short inter-pregnancy interval & $8(6.7)$ \\
\hline Economic reason & $9(7.6)$ \\
\hline High demanding career & $28(23.5)$ \\
\hline Unplanned pregnancy after family completion & $67(56.3)$ \\
\hline
\end{tabular}

$(67 ; 56.3 \%)$ had terminated the pregnancy due to reason of unplanned pregnancy after family completion. Almost all of the respondents (111;
93.3\%) had current pregnancy gestational age of less than 9 weeks and 68 (57.1\%) of them had undergone to medical abortion (Table. 1).

Table 2: Past history of use of family planning measures $(n=119)$

\begin{tabular}{|l|l|}
\hline Characteristics & \multicolumn{1}{|c|}{ Number (Percentage) } \\
\hline Use of contraceptive measures & $87(73.1)$ \\
\hline Yes & $32(26.9)$ \\
\hline No & \\
\hline Types of contraceptives used* (n=87) & $8(9.19)$ \\
\hline Intra Uterine Contraceptive Device (IUCD) & $12(13.79)$ \\
\hline Implant & $35(40.22)$ \\
\hline Condom & $26(29.88)$ \\
\hline Oral Contraceptives Pills (OCP) & $46(52.87)$ \\
\hline Depo-Provera (DEPO) & $40(45.97)$ \\
\hline Withdrawal & \\
\hline $\begin{array}{l}\text { Reasons for discontinuation of contraception } \\
\text { (n=87) }\end{array}$ & \\
\hline Side effects & $50(57.47)$ \\
\hline Missed a contraception cycle dose & $15(17.24)$ \\
\hline Desire for pregnancy & $6(6.89)$ \\
\hline Separation from husband & $16(18.39)$ \\
\hline $\begin{array}{l}\text { Reasons for not Using any Contraceptives } \\
\text { (n=32) }\end{array}$ & \\
\hline Fear of side effects & $29(90.62)$ \\
\hline Unawareness on contraceptives & $3(9.37)$ \\
\hline
\end{tabular}

Types of contraceptives used*: May exceed total number of 87 as the same respondent had used multiple contraceptive methods at different points of time.

Majority of the respondents $(87 ; 73.1 \%$ ) had used a modern method of contraception. Among them; almost half $(46 ; 52.87 \%)$ had used DEPO Provera, more than half $(57.47 \%)$ had discontinued contraceptives due to side effects and almost all $(29 ; 90.62 \%)$ had not used any form of contraception due to fear of side effects (Table 2).

Majority of the respondents $(90 ; 75.6 \%)$ had preferred some form of contraceptive measures post abortion. Among them, nearly half $(44 ; 48.9 \%)$ had preferred oral contraceptives followed by DEPO $(17 ; 18.9 \%)$ and IUCD $(16 ; 17.8 \%)$. Nearly one fourth $(24.4 \%)$ had not accepted any form of post abortion contraceptives. Among them, two third $(65.52 \%)$ of the respondents did not prefer any form of contraception due to fear of side effects (Table 3). 
Table 3: Use of post-abortion contraceptive methods in the current pregnancy $(n=119)$

\begin{tabular}{|l|l|}
\hline Characteristics & Number (Percentage) \\
\hline Use of post-abortion contraception method & \\
\hline Yes & $\mathbf{9 0} \mathbf{( 7 5 . 6 )}$ \\
\hline No & $\mathbf{2 9} \mathbf{2 4 . 4 )}$ \\
\hline Methods of contraception used (n=90) & \\
\hline OCP & $44(48.9)$ \\
\hline DEPO & $17(18.9)$ \\
\hline Implants & $16(17.8)$ \\
\hline IUCD & $19(14.4)$ \\
\hline Reasons for not using any form of contraception (n=29) & \\
\hline Want to get pregnant soon & $6(20.69)$ \\
\hline Separation with husband/partner & $4(13.79)$ \\
\hline Fear of side effects & $19(65.52)$ \\
\hline
\end{tabular}

Table 4: Association between socio-demographic variables and use of post-abortion contraceptives

\begin{tabular}{|l|l|l|l|l|}
\hline Characteristics & \multicolumn{2}{|l|}{$\begin{array}{l}\text { Use of Post-abortion contra- } \\
\text { ceptive }\end{array}$} & $\chi^{2}$ & $p$ value \\
\hline & Yes [n(\%)] & No [n(\%)] & & \\
\hline Education level & & & & \\
\hline Up to secondary & $42(85.7)$ & $7(14.3)$ & 6.640 & 0.01 \\
\hline Higher secondary and above & $39(63.9)$ & $22(36.1)$ & & \\
\hline Parity & & & & \\
\hline Nullipara & $13(46.4)$ & $15(53.6)$ & 16.941 & 0.000 \\
\hline Multipara & $77(84.6)$ & $14(15.4)$ & & \\
\hline Contraceptive use in past & & & & \\
\hline Yes & $71(81.6)$ & $16(18.4)$ & 6.275 & 0.01 \\
\hline No & $19(59.4)$ & $13(40.6)$ & & \\
\hline Plan of future pregnancy & & & & \\
\hline Yes & $23(57.5)$ & $17(42.5)$ & 10.764 & 0.001 \\
\hline No & $67(84.8)$ & $12(15.2)$ & & \\
\hline $\begin{array}{l}\text { Discussion about family planning } \\
\text { with partner }\end{array}$ & & & & \\
\hline Yes & $66(94.3)$ & $4(5.7)$ & 32.101 & 0.000 \\
\hline No & $24(49.0)$ & $25(51.0)$ & & \\
\hline
\end{tabular}

Significant association was noted between utilization of post abortion contraceptive and educational level ( $p$-value $=0.01)$. Similarly, contraceptive use in past, increased parity, plan of future pregnancy and discussion about family planning with partner were also found to be significantly associated with post-abortion contraceptive use. ( $p$-value $\leq 0.05)$ (Table 4). 


\section{Discussion}

The finding of this study showed that the majority $(90 ; 75.64 \%)$ of the respondents had used post abortion contraceptive which is similar to the finding of the study done by Hagos et al. in Ethiopia where $70.9 \%$ accepted post abortion contraceptive (9) but the finding of this study is in contrast to the study conducted by Padmadas et al (8). In Nepal, there was low level of post abortion contraceptive use and high rates of discontinuation, especially among women using modern temporary contraceptive methods in the year of 2014. Only 56\% women had an abortion initiated contraceptive use in the 12 months following the procedure. This clearly showed that there is an increasing trend in the practice of post-abortion contraceptive use.

In this study, nearly one fourth $(29 ; 24.36 \%)$ of the respondents did not accept post-abortion family planning method which is similar to the study done by Bista et al., in which $22.4 \%$ did not accepted post-abortion contraceptive (10). Also in this study, most $(87 ; 73.1 \%)$ of the respondents had used some form of contraceptive method in past, which is similar to the study done by Bhandari et al. in which almost all (90\%) of the respondent had used contraceptive in past (11).

The present study showed that three fifth (50; $57.47 \%$ ) of the respondents had discontinued the use of contraception in the past due to side effects which is in contrast to the study done by Khanal et al. in which nearly half (48\%) of the respondents had discontinued due to side effects (12). The findings may be inconsistent due to different study setting in these two studies. But the finding of this study is similar to the study done by Shrestha et al. in which more than half (58.6\%) had discontinued the use of contraception due to side effects (13).

Regarding the reproductive history, the present study revealed that most $(77 ; 84.6 \%)$ of the multiparous women had utilized some form of post-abortion contraceptive measures. Similar finding was seen in a study conducted by Onyegbule et al. where most of the multiparous women (80.9\%) accepted post abortion family planning (14).
In this study, almost all (111; 93.3\%) of the respondents terminated their current pregnancy at less than nine weeks gestation. The finding is in contrast to the study conducted by Matiyas et al. where two third $(66.7 \%)$ of the respondents terminated pregnancy at less than nine weeks gestation (15).

Regarding the method of abortion services; in this current study, three fifth $(68 ; 57.1 \%)$ of the respondents preferred medical abortion. The finding is in contrast to the study done by Matiyas et al. in which majority (88.6\%) of the respondents preferred surgical method (15). More than half (67; 56.3\%), terminated the current pregnancy due to reason of completed family which is in consistent with the study conducted by Bhandari et al. which stated that half $(50 \%)$ of the respondents terminated pregnancy due to the completed family (11).

The study showed that the majority (87; $73.1 \%$ ) of the respondents had history of use of some form of contraceptive method in past. This finding is in contrast to the study done by Shrestha et al. which showed that almost half (53.6\%) had history of use of some form of contraceptive method in past (13). Similarly in this study, among the contraceptive users in the past, more than half $(50 ; 57.47 \%)$ had discontinued due to side effects of contraceptives.

Regarding the post-abortion contraceptive use in the current pregnancy, the present study showed that nearly half $(44 ; 48.9 \%)$ of the respondents had preferred oral contraceptive pills followed by Depo-Provera $(17 ; 18.9 \%)$ after surgical or medical abortion. The finding of this study is in contrast to the study done by Shrestha et al. in which nearly one fourth $(22.8 \%)$ of the respondents had used Depo-Provera followed by oral contraceptive pills (19.6\%) following abortion (13). Similarly, the finding of the present study is in contrast to the study done by Azmat et al. in which nearly one third (31.6\%) had used intrauterine contraceptive device followed by the condom (29.1\%) (16).

Regarding the pregnancy termination, the present study showed that the main reason for termination of the current pregnancy was due to completed family $(67 ; 56.3 \%)$ followed by high 
demanding career $(28 ; 23.5 \%)$ and short inter pregnancy interval $(8 ; 6.7 \%)$. These findings are in consistent with the study done by Bhandari et $a l$. in which the main reasons for terminating the present pregnancy were completed family (43\%) followed by high demanding career (33\%) and short inter pregnancy interval (8\%) (11).

Regarding the association between use of post abortion contraceptive and socio-demographic characteristics, the findings of the current study showed that level of education, increasing parity, contraceptive use in past, plan of future pregnancy and discussion about family planning with the partner were significantly associated with post abortion contraceptive use $(p \leq 0.05)$. In this study, the contraceptive acceptance was lower in a higher educated group which is in contrast with the study finding done by Shrestha et al. in which the contraceptive acceptance was higher in a higher educated group (13). The present study findings are in contrast to the study done by Kokeb et al. in which age, marital status, occupation, type of clinic choose and history of previous abortion were significantly associated with post abortion contraceptive utilization with $p$-value $\leq 0.05$ (17).

But the findings of this study are in consistent with the study conducted by Hagos et al. in which parity, previous history of contraception use and discussion about family planning with husband were statistically significant with post abortion contraceptive use where $p$ value was $\leq 0.05$ (9).

\section{Conclusions}

There is an increasing trend in the use of postabortion contraceptive measures in Nepal after surgical or medical abortion from 56.0\% in 2014 to $75.64 \%$ in 2018 as seen in this study. Among the respondents who denied use of post abortion contraceptive measures do so due to fear of side effects. Post abortion contraceptive use significantly vary according to educational level, parity, contraceptive use in past, plan of future pregnancy and family planning discussion with husband or partner. Hence, raising the knowledge, attitude and practice of post-abortion contraceptive use and social awareness among women of reproductive age groups through various communities' participation, mass education via various commu- nication means would certainly help to decrease the proportion of unplanned future pregnancies and unsafe abortions which would significantly reduce the maternal morbidity and mortality. Also, sharing such scientific evidence would certainly reduce undue fear of the use of post-abortion contraceptive use and its side effects and also help to raise the acceptance and compliance of postabortion contraceptive uses.

\section{Acknowledgement}

I would like to acknowledge my debt to my research advisor Prof. Renuka Pradhananga; coadvisor Lecturer Tulza K.C.; Prof. Mandira Onta, Asst. Dean TUTH, Institute of Medicine; Associate Prof. Dr. Archana Pandey Bista, Head of the Department of Nursing Research and Education; Associate Prof. Prem Prasad Panta; Campus Chief Prof. Sulochana Shrestha; faculties of Women's Health and Development; library staffs; administrative members and Mr. Shyam Sundar Sapkota of Institute of medicine for their continuous support, insightful guidance, constructive feedbacks in the study.

Finally, I extend my heartfelt thanks to the Head and other staffs of Marie Stopes, Nepal for giving permission for and during the data collection. I am also truly indebted to all respondents for their participation and patience who made this study a reality.

\section{Disclosure}

The authors report no conflicts of interest in this work. No violation of human rights and safety.

\section{References}

1. Dirgha S, Sibesh R, Ganesh D. Abortion still unfinished agenda in Nepal, Nepal Health Research Council. 2018 ;16(1):93-98.

2. Bhandari BR, Jha R, Baral J, Wagle RR. Study of contraceptive use among comprehensive abortion care clients in family planning clinic of Tribhuvan university teaching hospital. Nepal Journal of Obstetrics and Gynaecology.2014; 9(2):22-26.

3. Seyoum D, Gebeyehu A, Gizaw Z. Assessment of post abortion contraceptive intention and associated factors among abortion clients in Gondar. Universal Journal of Public Health, 2014; 2(8):215225. 
4. Lamina MA. Prevalence of abortion and contraceptive practice among women seeking repeat induced abortion in Western Nigeria. Journal of Pregnancy, 2015;1-7.

5. Obare F, Liambila W, Birungi H. Family planning counselling and use among clients seeking abortion services in private health facilities in Kenya. Etude de La Population Africaine Journal. 2014; 28(3):1274-1285.

6. Zhang $\mathrm{WH}$, Che $\mathrm{Y}$, Chen $\mathrm{Q}$, Cheng L, Temmerman M. Contraception interventions for women seeking abortion. Cochrane Database of Systematic Reviews 2014, 14 Issue 4. Art. No.: CD011067.

7. Banerjee SK, Gulati S, Andersen KL, Acre V, Warvadekar J, Navin D. Associations between abortion services and acceptance of post-abortion contraception in six Indian states, Journal of Studies in Family Planning. 2015; 46(4):387- 403.

8. Padmadas SS, Lyons AM,Thapa S. Contraceptive behavior among women after abortion in Nepal. International Journal of Gynecology and Obstetrics. 2014; 127(2):132-137.

9. Hagos G, Tura G, Kahsay G, Haile K, Grum T. Family planning utilization and factors associated among women receiving abortion services in health facilities of central zone towns of Tigray, Northern Ethiopia. BMC Womens Health.2018; 18(1):1-8.

10. Bista KD, Pradhan N, Manandhar R. Knowledge, attitude and practice of contraception among women seeking abortion care services. Journal of Institute of Medicine. 2013; 2(35):45-51.

11. Bhandari BR, Jha R, Baral J, Wagle RR. Study of contraceptive use among comprehensive abortion care clients in family planning clinic of Tribhuban university teaching hospital. Nepal Journal of Obstetrics and Gynaecology. 2014; 9(2):22-26.

12. Khanal V, Joshi C, Neupane D, Karkee R. Practices and perceptions on contraception acceptance among clients availing safe abortion services in Nepal. Kathmandu University Medical Journal. 2011; 9(35):179-184.

13. Shrestha A, Sharma P. Post Abortion Choice and Acceptance of Contraception. Nepal Journal of Obstetrics and Gynaecology. 2013; 8(1):14-17.

14. Onyegbule 0 , Onumajuru C, Ododo N, Idih E, Onyegbule P. Uptake of post-abortion contraception among women who had manual vacuum aspiration at Federal Medical Centre. Journal of Obstetrics and Gynaecology. 2016; 33(2):228-234.

15. Matiyas A, Delayehu B, Rominski SD. Post-Abortion Contraceptive Acceptance and Choice Determinants Among Women Receiving Abortion Care at Saint Paul's Hospital, Addis Ababa, Ethiopia. Ethiopian Journal of Reproductive Health. 2018; 10:3548.

16. Azmat SK, Hameed W, Ishaque M, Mustafa G, Ahmed A. Post-abortion care family planning use in Pakistan. Pakistan Journal of Public. 2012; 2(2): 49.

17. Kokeb L, Endeshaw A, Hiwot K, Tewodros S. Utilization of post abortion Contraceptive and associated factors among women who came for abortion Service. Journal of Family Medicine and Disease Prevention. 2015; 2(10):4-7. 